\title{
FUNDAMENTOS DO DIREITO INTERTEMPORAL
}

José Eduardo Figueiredo de Andrade Martins

Mestre em Direito Civil pela Universidade de São Paulo. Especialista em Direito Constitucional pela Pontifícia Universidade Católica de São Paulo. Bacharel em Direito pela Pontifícia Universidade Católica de Campinas. Advogado e Professor do curso de Direito da Pontifícia Universidade Católica de Campinas.

RESUMO: Este artigo analisa o Direito Intertemporal, esclarecendo os fundamentos das principais teorias sobre a disciplina para a resolução dos conflitos da lei no tempo. A partir disso, são expostas as influências desse desenvolvimento teórico no ordenamento jurídico brasileiro.

Palavras-chave: Direito Intertemporal; Teoria Subjetivista; Teoria Objetivista; Conflito da lei no tempo.

ABSTRACT: This article analyzes the Intertemporal Law, clarifying the basics of the main theories on the subject for the resolution of conflicts of law in time. From this, the influences of this theoretical development in the Brazilian legal system are exposed.

Keywords: Intertemporal law; Subjective Theory; Objective Theory; Conflict of law in time

SUMÁRIO: Introdução. 1. O desenvolvimento do princípio da irretroatividade. 2. Teoria Subjetivista. 3. Teoria Objetivista. 4. Os problemas das teorias subjetivista e objetivista. 5. O Direito Intertemporal no Brasil. 6. Hipóteses de retroatividade das leis no ordenamento jurídico brasileiro. Conclusão.

\section{Introdução}

O Direito tem como característica a sua imperatividade, da qual se extrai a ideia de que a norma jurídica, como uma proposição, enuncia um dever ser. Inserida em determinado sistema, a norma ganha vida própria, já que ainda que seja o produto de uma vontade - um ato de vontade, no modo como nomeia Hans Kelsen (1998, p. 4) - a sua existência é independente e autônoma da força que a originou. 
Sendo, portanto, uma determinação de comportamentos, instruindo a maneira pela qual os indivíduos devem se portar, é notável que a atividade do legislador tem sobretudo, em regra, um caráter prospectivo: questões de interesse da coletividade são normatizadas para que a partir da vigência da norma jurídica é que haja inovação nas relações jurídicas já estabelecidas. A nova norma jurídica, então, tratará de criar, modificar ou extinguir um instituto jurídico, disciplinando de maneira diversa a conduta social ao mesmo tempo em que consolida aquilo que ocorreu em tempo pretérito.

Todavia, o advento de uma nova legislação nem sempre aparenta uma congruência com o sistema, suscitando dúvidas acerca dos efeitos jurídicos decorrentes ou até mesmo da própria consolidação de um ato realizado no passado. Surge então o grande impasse: sob a lei nova ou a velha é que se regerá esta relação jurídica?

Para tentar responder a este questionamento é que existe a disciplina do Direito Intertemporal, tratando, em termos sintéticos, dos conflitos da lei no tempo. Neste artigo serão analisados os seus principais fundamentos teóricos, além de expor as suas consequências no ordenamento jurídico brasileiro.

\section{O desenvolvimento do princípio da irretroatividade}

A fórmula do princípio da irretroatividade das leis preceitua basicamente que a lei nova não alcança os fatos praticados antes de sua vigência. Trata-se de exigência de respeito pelo legislador às relações jurídicas validamente firmadas no passado, sem que a lei nova prejudique seu desenvolvimento. Esse aspecto não deixa de ser uma decorrência do princípio da segurança jurídica, tendo em vista que busca garantir aos indivíduos um controle e limite sobre a força Estatal, admitindo aquilo que já se consolidou no passado, ainda que não seja mais do interesse deste a sua existência.

Também se funda na estabilidade das relações jurídicas, impedindo que haja surpresas por meios legislativos àquilo que fora pactuado no passado. Afinal, desestabilizar as relações é ir de encontro ao progresso social. Dessa maneira, a irretroatividade das leis deve se ajustar à tensão entre a solidez das relações jurídicas pré-estabelecidas e às novas exigências sociais (PEREIRA, 2005, p. 138).

O princípio da irretroatividade das leis já podia ser encontrado no Direito Romano, sendo a lei retroativa somente quando estivesse expressamente determinada. Essa regra pode ser encontrada no Codex, Livro I, título XIV, fr. 7 do Corpus Iuris 
Civilis: Leges et constitutiones futuris certum est dare formam negotiis, non ad facta praeteria revocari; nisi nominatim, et de praeterito tempore, et ad-huc pendentibus negotiis cautum ${ }^{1}$.

É possível também encontrá-lo no Direito Canônico que, se baseando no Direito Romano, mas influenciado obviamente pelo pensamento cristão, estabelece no cânon $\mathrm{n}^{\circ}$ 10 do Corpus Iuris Canonici que só poderia haver exceção para a consecução do bem comum ou por razões superiores, sofrendo limitação, portanto, daquilo que se sustentava ter natureza divina (PIRES, 2005, p. 108)2

Em sistemas jurídicos mais modernos, o princípio da irretroatividade também se faz presente, como na Constituição dos Estados Unidos da América de 1787 que, em seu artigo $1^{\circ}$, seção $5^{a}$, dispõe que o Congresso não poderá editar leis com efeito retroativo. O Código Civil Napoleônico proibiu em seu artigo $2^{\circ}$ o efeito retroativo das leis, permitindo somente o efeito prospectivo, regra repetida pelo Código Civil italiano em seu artigo 11 . No artigo $3^{\circ}$ do Código Civil espanhol há a ressalva de excepcionar a irretroatividade se assim dispuser o legislador na nova lei.

Dentre os diplomas modernos destaca-se o BGB que não possui uma regra própria para a resolução dos conflitos da lei no tempo. Para a doutrina alemã a retroatividade deve ser admitida quando decorrente da manifesta e clara vontade do legislador, ainda que não expressa. Sendo assim, a lei não deve ser entendida como irretroativa genericamente, pois o efeito prospectivo é decorrência lógica do sistema, sendo questionado somente diante de uma investigação da voluntas legislatoris (PEREIRA, 2005, p. 143).

Paralelamente e em contribuição ao desenvolvimento de referidos diplomas legais, surgiram duas importantes correntes teóricas buscando explicar o fenômeno do conflito das leis no tempo e seus efeitos decorrentes: as teorias subjetivistas e objetivistas. Ainda que a partir de bases teóricas distintas, suas conclusões são bastante semelhantes, mas não idênticas, como procuraremos demonstrar a seguir.

\footnotetext{
${ }^{1}$ É certo que as leis e constituições dão forma a negócios futuros, e não aos fatos pretéritos, a menos que haja disposição expressa para o tempo passado e para negócios pendentes. (Tradução livre)

${ }^{2}$ No atual Código de Direito Canônico (Codex Iuris Canonici) o princípio da irretroatividade se encontra no cânon 9, dispondo que as leis visam o futuro, e não o passado, a não ser que explicitamente nelas se disponha algo sobre o passado. Nota-se uma aproximação aqui com o conceito moderno de irretroatividade, bem como à noção original do Direito Romano.
} 


\section{Teoria Subjetivista}

Motivo de acalorados debates acadêmicos, o conceito de direito subjetivo é ainda controverso. Para Windscheid (1906, p. 37), direitos subjetivos são somente reflexos de uma ordem jurídica, sendo o agir assegurado pela ordem jurídica, tendo a vontade como essencial.

Ihering (1924, p. 338) insurge-se contra esta concepção, entendendo que o proveito constitui a substância do direito, e não a vontade. O direito subjetivo é um poder jurídico, mas sua finalidade é a satisfação dos interesses humanos. Trata-se, assim, de um interesse juridicamente protegido.

Hans Kelsen (2000, p. 124), por sua vez, entende que direitos subjetivos são liberdades asseguradas objetiva e juridicamente. A validade do direito é encontrada de maneira deontológica, isto é, as proposições jurídicas é que estabelecem as liberdades de ação. Não há, pois, proteção do direito subjetivo, mas sua previsão no plano deontológico da ordem jurídica.

Por fim, Miguel Reale (2001, p. 244) procura trazer sua própria definição de direito subjetivo, como a possibilidade de exigir-se, de maneira garantida, aquilo que as normas de direito atribuem a alguém como próprio.

Nenhuma das noções se mostra suficiente para explicar o fenômeno, principalmente em razão de cada uma partir de bases distintas de noção da própria natureza do Direito. Ainda assim, é possível extrair a ideia de que todas pretendem proteger aquilo que é reconhecidamente próprio do indivíduo, seja por uma ordem objetivada ou não. Essa estrutura é essencial para entender a influência que a doutrina dos direitos subjetivos teve para o desenvolvimento da teoria subjetivista do Direito Intertemporal.

Também conhecida como Doutrina Clássica, a teoria subjetivista prega o conceito de direito adquirido como piso para as conclusões sobre a aplicação das leis no tempo, variando seus elementos essenciais conforme o estudioso do tema. Foi concebida inicialmente na França no século XIX a partir da Escola da Exegese, mas também se desenvolveu na Alemanha e Itália. 
O francês Merlin de Douai entende que, como princípio geral, a lei não tem efeito retroativo, mas pode retrooperar. A lei nova pode, portanto, até alcançar e mudar o passado, prejudicando as pessoas com ela relacionadas, mas só se caracterizará um gravame quando há um direito adquirido atingido (PIRES, 2005, p. 117).

Distingue direito adquirido, faculdade e expectativa de direito. Para o autor, o direito adquirido, atrelado à patrimonialidade, é aquele que entra no domínio do indivíduo e, consequentemente, forma parte dele e não pode ser desfeito. Faculdade, por sua vez, é a possibilidade jurídica de se praticar determinado ato. Expectativa é a situação em curso, na qual se tem apenas uma esperança de se adquirir um direito caso ocorra um acontecimento futuro que lhe dê efetividade (NADER, 2015, p. 253).

Na Alemanha, Frederico K. Von Savigny (1898, p. 382-384) estrutura seu pensamento na ideia que não se deve atribuir força retroativa às novas leis, restando intactos os direitos adquiridos. Só será admissível quando a norma jurídica tratar da existência, extinção ou modo de existência do direito, por atender aos propósitos próprios de justiça (PIRES, 2005, p. 119), além dos casos em que o próprio legislador se manifesta positiva e expressamente neste sentido.

O que chama de "natureza das coisas" é o que fundamenta a irretroatividade das leis. Trata-se daquilo que se naturalmente percebe, determinado pelo próprio funcionamento natural do mundo. Para Savigny, essa limitação é imposta tanto ao legislador quanto ao intérprete, em acepção idêntica àquela do sistema interpretativo da livre investigação científica do Direito, embora Savigny esteja entre aqueles filiados ao sistema histórico-evolutivo.

Em seu pensamento também há a diferenciação entre direito adquirido, faculdades jurídicas abstratas e expectativa de direito, e acrescenta os chamados direitos não exercitáveis. O conceito de direito adquirido consiste na conjunção do direito com um indivíduo ou um grupo de indivíduos, o que não se difere muito daquele desenvolvido por Merlin. Faculdades jurídicas abstratas são aqueles direitos postos, mas não exercitados pelo potencial titular, isto é, potencialmente podendo se tornar direitos adquiridos. Expectativa de direito é aquela dependente do mero arbítrio de outrem. E direitos não exercitáveis são aqueles que estão sob uma condição ou termo, ou seja, independem do arbítrio de outrem, e seu cumprimento tem efeito retroativo (PIRES, 2005, p. 119). 
Contribuindo para a doutrina alemã, Ferdinand Lassalle sistematiza a teoria dos direitos adquiridos. O pensamento do autor se finca em dois postulados fundamentais: (a) nenhuma lei pode retroagir se atinge um indivíduo através de seus atos de vontade e (b) toda lei pode retroagir se o atinge fora dos seus atos de vontade, ou seja, nas qualidades que lhe são comuns com a humanidade inteira ou que obtém da sociedade ou se ao atingi-lo, modifica também a sociedade nas suas instituições orgânicas (PEREIRA, 2005, p. 148).

A principal crítica que se faz a Lassalle é quanto a sua concepção de direito adquirido constituído somente em razão da ação livre da vontade do indivíduo, ignorando a constituição de direito adquirido através da lei e a atribuição de retroatividade àquilo que pode atentar contra toda a humanidade, violando a própria dignidade da pessoa humana. De fato, não se pode admitir que somente a liberdade individual constitua direitos adquiridos e que direitos humanos podem ser violados livremente, embora existam outras normas e instrumentos jurídicos além do princípio da irretroatividade das leis para protegê-los. Assim, é notável que a concepção de Ferdinand Lassalle não se expande para todas as espécies de direitos nos mais variados ramos, razão pela qual foi prontamente abandonada.

A grande consolidação da teoria subjetivista veio com o pensamento do jurista italiano Carlo Francesco Gabba. Construindo larga doutrina sobre o tema do Direito Intertemporal, determinou como regra essencial a impossibilidade de a lei nova violar direitos precedentemente adquiridos, mas caso não estes não sejam afetados, a nova lei pode ser aplicada de maneira ampla, integrando tanto os fatos e relações jurídicas novas quanto os efeitos dos anteriores (GABBA, 1891, p. 140-141).

No seu pensamento estão presentes os conceitos de direito adquirido, direito consumado, faculdades legais e expectativas de direito. De índole primordialmente patrimonial, direito adquirido é o

“[...] que foi criado sob o império de uma lei qualquer e que se tornou, imediatamente, parte do patrimônio do indivíduo, ainda que a ocasião de fazê-lo valer só apareça após a entrada em vigor de uma lei diferente (ROUBIER apud PIRES, 2005, p. 124)" (Tradução livre). 
Desse modo, só é reconhecida a existência de um direito adquirido se o seu fato gerador se decorreu por completo, seja ele um fato simples ou complexo, se integrando ao patrimônio do indivíduo. O que não se confunde com o direito consumado, por este já ter produzido todos os seus efeitos, não ser mais de interesse saber se há incidência da nova lei.

Expectativa de direito é um fato aquisitivo incompleto, uma mera esperança do indivíduo de o direito se tornar um direito adquirido. Por fim, faculdade legal é um poder concedido ao indivíduo pela lei ainda não utilizado por ele. Ambos institutos podem ser afetados pela lei nova.

\section{Teoria Objetivista}

Ainda que não goze do mesmo prestígio que a teoria subjetivista, por diversos motivos que alcançam até mesmo o aspecto individualista intrínseco ao espírito humano, a teoria objetivista estabelece bases científicas bastante sólidas para solucionar os conflitos de Direito intertemporal. No entanto, mesmo que possam ser reunidos vários autores sob a mesma corrente, é certo que cada um desenvolve de maneira particular seu pensamento, não sendo possível trabalhá-la senão expondo a ideia de seus principais expoentes. Para este estudo, serão analisados três deles: Julien Bonnecase, Paul Roubier e Henri de Page.

Julien Bonnecase, em crítica a construção de Baudry-lacantinère e Houquesfourcade, define as regras de Direito intertemporal a partir da situação jurídica, a qual define como a posição de uma pessoa em relação à lei, que pode ser dividida entre situação jurídica abstrata e concreta. Fala-se em situação jurídica abstrata quando não há a realização do ato ou fato jurídico pela pessoa que a colocaria sob os efeitos da lei. Sendo assim, a pessoa não é alcançada pela lei, devendo ser entendida a expressão como uma substituição do termo "expectativa de direito" (BONNECASE, 1935, p. 169). Já a situação jurídica concreta, por sua vez, ocorre quando há o alcance da pessoa pela regra, haja vista que o ato ou fato jurídico foi realizado e a lei, por isso, produz efeitos sobre ele. Deve-se, assim, utilizar o conceito de situação jurídica concreta como substituto ao conceito de "direito adquirido". Para este autor, a retroatividade da lei só é vedada nas situações jurídicas concretas, sendo admitidas nas abstratas (BONNECASE, 1935, p. 225). Embora de grande importância, esse pensamento tende a ser insuficiente dada a 
sua simplificação, ignorando a complexidade das relações jurídicas e o tratamento legal concedido a elas.

Paul Roubier foi um dos maiores críticos à teoria subjetivista, entrando em franco debate contra os seus autores, sobretudo Savigny, E a partir de suas críticas desenvolve sua própria teoria, fundada na ideia do facta praeterita, com raízes no Pandectismo. O autor identifica três efeitos da lei em relação ao tempo: efeito retroativo, efeito imediato e efeito diferido. Quando atinge os fatos já consumados, isto é, atos e fatos do passado (facta praeterita), seu efeito é retroativo. Se a ação da lei atinge somente fatos do presente (facta pendentia), seu efeito é imediato quanto às suas partes posteriores, mantendo-se intactas as partes anteriores. Por fim, se a lei alcança fatos futuros (facta futura), seu efeito é diferido, atingindo as situações jurídicas e seus efeitos na totalidade. O problema decorre do conflito dos efeitos retroativo e imediato, o que, para Roubier, se resolve na seguinte fórmula: a lei somente deve alcançar os fatos do presente, respeitando os fatos pretéritos e estendendo seu alcance sobre os efeitos futuros das situações jurídicas consolidadas quando ainda não produzidos ${ }^{3}$.

Deve-se abandonar a noção de direito adquirido, por fazer referência ao caráter subjetivo, e adotar o critério da situação jurídica, pois se trata de noção oponível a qualquer pessoa, alcançando relações unilaterais e bilaterais e todos os ramos do Direito (PEREIRA, 2005, p. 155). A situação jurídica se divide em uma fase dinâmica, em que se constitui ou extingue, e uma fase estática, correspondente à produção de seus efeitos.

A fase dinâmica é regida por duas regras essenciais, a depender do tempo que se decorre para constituir ou extinguir a situação jurídica. Se ela já estiver constituída no momento do advento da lei nova, esta não poderá atingi-la. Se a constituição ou extinção da situação jurídica ainda estiver em curso, a lei nova não pode atingir os elementos já existentes que fazem parte desta constituição ou extinção.

No tocante a fase estática, os efeitos da situação jurídica inteiramente constituída ou extinta são atingidos pela lei nova, se ainda não produzidos. Entretanto, se ainda há efeitos a serem produzidos, só estes serão atingidos pela lei nova, mantendo-se intactos os anteriores regidos pela lei anterior (PEREIRA, 2005, p. 156-157).

Henri de Page, comungando da solidez da teoria objetivista, desenvolve quatro regras para solucionar os conflitos de leis no tempo, deixando claro que é muito mais

\footnotetext{
${ }^{3}$ Roubier excepciona essa regra para alguns casos, como na celebração de um contrato em que suas consequências estão submetidas à lei anterior (MÁYNEZ, 2002, p. 394). 
conveniente que o próprio legislador os resolva preventivamente através de dispositivos transitórios. As quatro regras são as seguintes: (a) a lei nova não atinge as situações nascidas e definitivamente cumpridas sob o império da lei antiga; (b) a lei nova aplicase imediatamente, mesmo aos efeitos futuros das situações nascidas sob o império da lei anterior; (c) os contratos nascidos sob o império da lei antiga permanecem a ela submetidos, mesmo quando os seus efeitos se desenvolvem sob o domínio da lei nova; e (d) a lei nova aplica-se aos contratos em curso quando o legislador o declara expressamente ou quando a lei nova é de ordem pública (PEREIRA, 2005, p. 152-153).

Mesmo com o esforço de seus autores para demonstrar os equívocos da teoria subjetivista, os objetivistas não conseguiram que suas idéias fossem adotadas pela maioria dos países. Exemplo, contudo, que mostra a sua persistência nos dias atuais é o novo Código Civil e Comercial da Nação de 2015, que em seu artigo $7^{\circ}$ dispõe que as leis, a partir da sua entrada em vigor, se aplicam às consequências das relações e situações jurídicas já existentes, não tendo efeito retroativo salvo se houver dispositivo em contrário e não podendo atingir direitos amparados por garantias constitucionais. $\mathrm{O}$ novo dispositivo legal segue a mesma orientação do antigo artigo $3^{\circ}$ do revogado Código Civil argentino 4 .

\section{Os problemas das teorias subjetivista e objetivista}

Já evidenciado pelo próprio modo de pensar da teoria objetivista - a qual inclusive acusa a doutrina do direito adquirido de falsidade conceitual -, a teoria subjetivista possui outras falhas que a expõem como insuficiente para resolver todos os conflitos da lei no tempo, ainda que amplamente adotada pela maioria dos países ocidentais. Uma das razões principais consiste na dificuldade em se apontar quais direitos são tidos como adquiridos, o que acaba por determinar definitivamente se a lei nova poderá retroagir ou não.

Ademais, parece a teoria subjetivista dar guarida maior à retroatividade das leis ao invés da irretroatividade: todas as leis novas podem retroagir, salvo se atingirem direitos adquiridos. Se não se sabe quais direitos são verdadeiramente adquiridos, há aqui uma forte insegurança sobre a proteção das relações jurídicas, afetando diretamente

\footnotetext{
${ }^{4}$ A única mudança se dá quanto às regras mais favoráveis ao consumidor nas relações de consumo que envolvam as novas leis supletivas que, via de regra, não são aplicáveis aos contratos em execução. 
os fundamentos da segurança jurídica e da estabilidade das relações jurídicas que estruturam o princípio da irretroatividade das leis.

Caio Mário da Silva Pereira também denuncia outras falhas:

“[...] na sua aplicação prática os tribunais criam uma série absurda de confusões, desde o enunciado de um círculo vicioso ("direito adquirido é aquele que não pode ser atingido pela lei nova") com a inversão da causa e do efeito, até a extensão deste conceito a situações que não o comportam. Muito embora Gabba tenha examinado desveladamente o assunto, o problema dos direitos condicionais à luz da definição de direito adquirido constitui a eterna praga para quem tenha de lavrar na seara do direito intertemporal. Se por um lado a questão diante do fato aquisitivo simples é singela no seu enquadramento, em face do fato aquisitivo complexo cria às vezes situações de resolução extremamente difícil, para as quais a teoria dos direitos adquiridos não oferece subsídio perfeito (PEREIRA, 2005, p. 150-151)”.

Já a teoria objetivista também não se mostra perfeita. Como exemplo, temos que o pensamento de Paul Roubier não escapou de críticas, e não somente daqueles filiados à teoria subjetivista. José Carlos Moreira Alves questiona as bases ditas lógicas definidas pelo autor francês:

"Essas colocações são manifestamente equivocadas, pois dúvida não há de que, se a lei alcançar os efeitos futuros de contratos celebrados anteriormente a ela, será essa lei retroativa porque vai interferir na causa, que é um ato ou fato ocorrido no passado. Nesse caso, a aplicação imediata se faz, mas com efeito retroativo.” (ALVES, 2002, p. 582)

A mesma crítica é feita por Máynez (2002, p. 394-396), considerando incorreta a distinção de aplicação de leis entre os efeitos realizados e efeitos futuros. Afinal, se os efeitos futuros ainda não realizados forem afetados pela lei nova, isso significa que ela é retroativa, pois vai interferir diretamente naquilo que existia antes mesmo de a lei nova iniciar sua vigência. 
Por isso, equivocam-se aqueles que não vêem distinção nítida e prática entre as teorias subjetivista e objetivista ${ }^{5}$. É notável que no caso específico dos efeitos ainda não realizados as teorias divirjam. Caso a teoria subjetivista seja adotada, há aplicação da lei antiga; caso a teoria objetivista seja adotada, aplica-se a lei nova.

\section{O Direito intertemporal no Brasil}

O Direito brasileiro seguiu a orientação da maioria dos ordenamentos jurídicos do mundo, adotando expressamente em todas as suas Constituições, salvo a de 1937, o princípio da irretroatividade das leis. O mandamento é de que a lei não prejudicará o direito adquirido, o ato jurídico perfeito e a coisa julgada.

Para a teoria geral do Direito a proteção ao direito adquirido - utilizada aqui como gênero para englobar as espécies direito adquirido (stricto sensu), ato jurídico perfeito e coisa julgada - como orientação do sistema é de suma importância, pois expõe a filiação do ordenamento jurídico brasileiro à teoria subjetivista. Para o Direito pátrio, portanto, encarar o conflito das leis no tempo é fazê-lo em face dos direitos subjetivos individuais.

Contudo, a exceção da Constituição de 1937 mostra que nem sempre foi assim. No período de sua vigência, foi editado o Decreto-lei no 4.657 de 1942 , conhecido à época como Lei de Introdução ao Código Civil Brasileiro ${ }^{6}$, que em seu artigo $6^{\circ}$ dispunha que a lei, salvo disposição expressa em contrário, não atingiria as situações jurídicas definitivamente constituídas e a execução do ato jurídico perfeito. Por um breve momento, até o retorno para a tradicional orientação subjetivista pela Constituição de 1946 e pela Lei $n^{\circ} 3.238$ de 1957, o ordenamento jurídico brasileiro adotou a posição objetivista.

Tanto o artigo $6^{\circ}$ da Lei de Introdução às Normas do Direito Brasileiro quanto o artigo 5, XXXVI da Constituição Federal de 1988 fazem referência às três espécies de direitos adquiridos, sendo que a primeira chega a conceituá-los em seus parágrafos. Ato jurídico perfeito é o já consumado segundo a lei vigente ao tempo em que se efetuou. Direitos adquiridos (stricto sensu) são os direitos que o seu titular, ou alguém por ele, possa exercer, como aqueles cujo começo do exercício tenha termo pré-fixo, ou

\footnotetext{
${ }^{5}$ Por isso que não podemos concordar com a afirmação feita por Caio Mário da Silva Pereira que as teorias não se difiram fundamentalmente (PEREIRA, 2005, p. 157).

${ }^{6}$ Hoje renomeado pela Lei no 12.376 de 2010 como Lei de Introdução às normas do Direito Brasileiro. 
condição pré-estabelecida inalterável, a arbítrio de outrem. Coisa julgada é a decisão judicial da qual já não caiba recurso.

É indistinta a proteção e limite no que concerne o direito privado e o direito público, não podendo a lei violar um direito adquirido, seja ele de qual ordem for. Já a criação, modificação e extinção de instituições jurídicas têm aplicação imediata, haja vista serem meras faculdades jurídicas, pendentes para uso do indivíduo. Não tem a lei nova vinculação à sua observância no caso de extinção ou de referência ao seu antigo estado no caso de modificação.

Curiosa, contudo, é a redação do artigo 14 do Novo Código de Processo Civil, ao dispor que a norma processual não retroagirá e será aplicável imediatamente aos processos em curso, respeitados os atos processuais praticados e as situações jurídicas consolidadas sob a vigência da norma revogada. No momento em que o dispositivo processual fala em "situações jurídicas consolidadas", apresenta nítida filiação à teoria objetivista, postura eivada de inconstitucionalidade. Isto porque se o constituinte originário adotou a proteção ao direito adquirido, não pode a legislação infraconstitucional assimilar postura diversa.

Fica evidente neste dispositivo a escassa atenção dada aos fundamentos do Direito Intertemporal, no criticável e inadequado entendimento de que se tratam ambas as teorias subjetivistas e objetivistas de correntes que partem de premissas diferentes, mas que chegam aos mesmos resultados. Dessa maneira, no momento em que o artigo 14 do Novo Código de Processo Civil fala de "situações jurídicas consolidadas", devese entender como um "direito (processual) adquirido", já praticado e estabilizado sob a vigência da norma revogada.

\section{Hipóteses de retroatividade das leis no ordenamento jurídico brasileiro}

Em algumas hipóteses a lei poderá retroagir, não se falando em direito adquirido. A situação mais comum que se costuma lembrar é a da lei material penal, que poderá retroagir para beneficiar o réu. Tal garantia encontra guarida no artigo $5^{\circ}$, inciso XL da Constituição Federal.

Ocorre que também deve ser lembrado que não há direito adquirido contra a Constituição Federal. Por isso, caso não haja previsão expressa ou se trate de direito que conflite com a nova ordem constitucional, não se pode falar em proteção daquilo que já 
fora constituído no passado. Um caso de previsão expressa é o artigo 51 do Ato das Disposições Constitucionais Transitórias, que permite a revisão pelo Congresso Nacional, através de Comissão mista, nos três anos a contar da data da promulgação da Constituição, todas as doações, vendas e concessões de terras públicas com área superior a três mil hectares, realizadas no período de $1^{\circ}$ de janeiro de 1962 a 31 de dezembro de 1987.

Também poderá retroagir a lei política, pois não se cristalizam direitos adquiridos no seu âmbito, salvo se houver alguma proteção individual. Caio Mário da Silva Pereira traz exemplo elucidativo:

"Se uma lei nova declara que ficam sem efeito as inscrições eleitorais anteriores, e determina que todo cidadão deve requerer novo título, aplica-se a todos, sem que ninguém possa opor à nova disposição a circunstância de já se ter qualificado anteriormente" (PEREIRA, 2005, p. 161).

Outra situação em que se admite a retroatividade da lei é quando se trata de lei meramente interpretativa. Compreende-se que a lei interpretativa não inova no ordenamento jurídico, haja vista que apenas traz o exercício hermenêutico autêntico do legislador. $\mathrm{O}$ que não significa que poderá atingir direitos adquiridos antes do advento da lei interpretativa, pois estes já estarão consolidados e não podem ser alterados.

Igualmente, a lei poderá retroagir em matéria tributária nos casos definidos no artigo 106 do Código Tributário Nacional. A lei terá efeito retroativo quando tiver natureza interpretativa (mas não podendo aplicar penalidades a qualquer infração dos dispositivos interpretados) e quando não houver coisa julgada contra ato que deixou de ser definido como infração, de ser tratado como contrário a qualquer exigência de ação ou omissão, desde que não tenha sido fraudulento e não tenha implicado em falta de pagamento de tributo ou comine penalidade menos severa que a prevista na lei vigente ao tempo da sua prática.

Há o caso do efeito repristinatório como uma exceção à irretroatividade das leis. Não se pode confundir com repristinação: enquanto neste há a restauração da lei revogada por ter a lei revogadora perdido a vigência - e, no caso brasileiro, por menção expressa da lei que revogou a lei revogadora, nos termos do artigo $2^{\circ}$, parágrafo $3^{\circ}$ da Lei de Introdução às Normas do Direito Brasileiro -, o efeito repristinatório ocorre pela 
declaração de inconstitucionalidade da lei revogadora, restaurando a eficácia das leis afetadas. Assim já decidiu o Supremo Tribunal Federal:

“A declaração de inconstitucionalidade de uma lei alcança, inclusive, os atos pretéritos com base nela praticados, eis que o reconhecimento desse supremo vício jurídico, que inquina de total nulidade os atos emanados do Poder Público, desampara as situações constituídas sob sua égide e inibe - ante a sua inaptidão para produzir efeitos jurídicos válidos - a possibilidade de invocação de qualquer direito. A declaração de inconstitucionalidade em tese encerra um juízo de exclusão, que, fundado numa competência de rejeição deferida ao Supremo Tribunal Federal, consiste em remover do ordenamento positivo a manifestação estatal inválida e desconforme ao modelo plasmado na Carta Política, com todas as consequências daí decorrentes, inclusive a plena restauração de eficácia das leis e das normas afetadas pelo ato declarado inconstitucional"7.

Por fim, há a polêmica hipótese da relativização da coisa julgada. Como se trata de decisão da qual não cabe mais recurso, é de se esperar que ela faça "lei entre as partes”. Entretanto, em situações bastante específicas, é admitida a sua relativização, permitindo que sejam desconstituídos direitos adquiridos anteriormente. Um primeiro caso se encontra previsto no Novo Código de Processo Civil, trilhando a mesma orientação do diploma processual anterior.

Os artigos 525, parágrafo 12 e 535, parágrafo $5^{\circ}$ tornam inexigíveis títulos executivos lastreados em legislação declarada inconstitucional pelo Supremo Tribunal Federal. Ou seja: mesmo que se trate de títulos oriundos de atos jurídicos perfeitos ou de coisa julgada, poderão ser tornados sem efeito com a declaração por controle de constitucionalidade concentrado ou difuso do Supremo Tribunal Federal.

Outro caso, decorrente de posicionamento do nosso tribunal constitucional, é a relativização da coisa julgada em ação de investigação de paternidade julgada extinta por ausência de provas. Nessa hipótese, ponderando os princípios da dignidade da pessoa humana e da segurança jurídica, restou decidido que é possível uma nova

\footnotetext{
${ }^{7}$ BRASIL. Supremo Tribunal Federal, Pleno. Ac. Un. ADI nº 652-5/MA. Questão de Ordem. Rel. Min. Celso de Mello. DJU 02.04.93.
} 
propositura da ação de investigação de paternidade, pois é direito do indivíduo ter acesso à informação genética e, por conseguinte, direito da personalidade ${ }^{8}$.

\section{Conclusão}

A pretensão deste estudo era demonstrar a importância dos fundamentos de Direito Intertemporal para a aplicação do Direito. Através de um resgate histórico e do desenvolvimento das principais teorias e estruturas sobre o tema, foi possível notar que o Direito Intertemporal é extremamente necessário para a exata compreensão daquilo que pode ser exigido e respeitado com o advento de uma nova lei.

Embora partam de estruturas distintas, as teorias subjetiva e objetiva acabam por chegar a conclusões bastante semelhantes. Ocorre, contudo, que não são idênticas, causando perplexidade quando se está diante de efeitos ainda não realizados de direitos adquiridos ou situações jurídicas consolidadas na vigência da lei velha.

O ordenamento jurídico brasileiro nitidamente adotou a teoria subjetivista, a qual preza pela proteção aos direitos adquiridos, englobando em seu conceito o direito adquirido stricto sensu, o ato jurídico perfeito e a coisa julgada. Assim, a partir dessa concepção, foi possível verificar que as exceções à irretroatividade da lei no Brasil se apresentam sobretudo em dispositivos normativos específicos e no exercício hermenêutico de princípios norteadores do sistema jurídico brasileiro.

\section{Referências Bibliográficas}

ALVES, José Carlos Moreira. Direito Adquirido. Fórum Administrativo, Belo Horizonte, v. 2, n. 15, p. 579-587, maio de 2002.

BONNECASE, Julien. Supplément au Traité Théorique et Pratique de Droit Civil de Baudry-Lacantinerie vol. II. Paris: Recueil Sirey, 1935.

DWORKIN, Ronald. O império do direito. $3^{\text {a }}$ ed. São Paulo: Martins Fontes, 2014.

GABBA, Carlo Francesco. Teoria della retroattività delle legge. v. 1, t. 1. Torino: Unione, 1891.

\footnotetext{
${ }^{8}$ BRASIL. Supremo Tribunal Federal, Pleno. RE no $363.889 / D F$. Rel. Min. Dias Toffoli. DJU
} 07.04.2011.

http://revistasapereaude.org/index.php/edicoes/ano-5-volume-1-agosto-2016 
IHERING, Rudolph Von. Der Geist des römischen Rechts auf den verschiedenen Stufen seiner Entwicklung. Leipzig: Leipzig Breitkopf und Hartel, 1924.

KELSEN, Hans. Teoria Geral do Direito e do Estado. $3^{\text {a }}$ ed. São Paulo: Martins Fontes, 2000 .

Teoria Pura do Direito. Tradução de João Baptista Machado. 6a ed. São Paulo: Martins Fontes, 1998.

MÁYNEZ, Eduardo García. Introduccion al estúdio del Derecho. 53ª ed. México: Porrua, 2002.

NADER, Paulo. Introdução ao Estudo do Direito. $37^{\mathrm{a}}$ ed. rev. e atual. Rio de Janeiro: Forense, 2015.

PEIXOTO, Ravi. Superação do precedente e segurança jurídica. Salvador: Juspodivm, 2015 .

PEREIRA, Caio Mário da Silva. Instituições de Direito Civil : vol. I. Rio de Janeiro: Forense, 2005.

PIRES, Maria Coeli Simões. Direito adquirido e ordem pública: segurança jurídica e transformação democrática. Belo Horizonte: Del Rey, 2005.

REALE, Miguel. Lições Preliminares de Direito. 25 ed. São Paulo: Saraiva, 2001.

SAVIGNY, Frederico K. Von. Sistema del diritto romano attuale : v. VIII. Trad. Scialoja. Turim: [s.n.], 1898.

WINDSCHEID, Bernhard. Lehrbuch des Pandektenrechts. Vol. 2. Frankfurt: Frankfurt a. M. Literarische Anstalt Rütten \& Loening, 1906. parág. 37. 